\title{
Câncer de Mama
}

\author{
Breast Cancer
}

0 estado atual da M astologia tem permitido detectar mais freqüentemente lesões neoplásicas iniciais, como o carcinoma ductal in situ.

$\mathrm{N} 0$ âmbito das especialidades oncológicas, o tratamento do câncer de mama inicia-se pela avaliação do tamanho da lesão, da margem de ressecção (se acometida, ou não) e da variedade histopatológica do tumor (carcinoma dos tipos comedo e não comedo). D eve-se valorizar, também, as características da imagem mamográfica e as condições da paciente, inclusive o seu acesso ao tratamento, bem como a sua vontade de preservar a mama.

A cirurgia conservadora, hoje, é uma realidade incontestável e, cada vez mais, têm surgido dados que autorizam realizá-la com mais segurança e um bom resultado estético.

0 objetivo do tratamento do câncer de mama no IN CA é buscar o melhor resultado de sobrevida com um mínimo de perda estética, com base em condutas definitivamente estabelecidas.

\section{EXAMES DE AVALIAÇÃO}

\section{CONFIRMAÇÃO DIAGNÓSTICA}

D e uma maneira didática, o tumor mamário mais comum (carcinoma ductal infiltrante/ CDI), para efeito de confirmação diagnóstica, foi dividido em palpável e impalpável. 0 tumor impalpável pode aparecer como:

- microcalcificações agrupadas;

- distorção do parênquima mamário;

- neo-densidade localizada; ou

- presença de tumores de tamanhos variados que, por conta do volume da mama, são impal páveis.

$\mathrm{N}$ as três primeiras formas de apresentação acima especificadas, faz-se a marcação percutânea orientada por estereotaxia radiológica e então, sob anestesia geral, removese a área doente ou alterada.
D urante 0 ato operatório, a radiografia da peça cirúrgica é de fundamental importância para se certificar de que a lesão está inclusa e foi completamente removida. 0 estudo anátomo-patológico deve ser do espécime incluso em parafina, que permite a adequada conservação do material, inclusive para avaliação dos receptores tumorais de estrogênio (RE) e de progesterona (RP).

Já os tumores impalpáveis podem ter sua marcação orientada por meio de estereotaxia radiológica ou ultra-sonográfica. N estes casos, os tumores podem ser estudados por exame histopatológico em congelação e, dependendo deste ter um resultado positivo para malignidade, e estando a mulher ou seu responsável legal devidamente concordantes, o tratamento cirúrgico definitivo do caso é realizado no mesmo ato operatório. Caso contrário, espera-se pelo resultado do exameanátomo-patológico do material incluso em parafina para se estabelecer o tratamento cirúrgico do caso.

$\mathrm{N}$ os casos de tumores palpáveis, utilizase, preferencialmente, a biópsia com agulha grossa (core-biopsy), sob anestesia local (pequena infiltração da pele), sendo obtidos pequenos fragmentos do tumor, suficientes para o exame patológico, inclusive a avaliação de RE e de RP.

A punção aspirativa com agulha fina (PAAF) é reservada para a avaliação de lesão secundária (nódulo supraclavicular ou axilar, nódulo mamário contralateral, etc.).

Atualmente, no IN CA, são matriculados apenas os casos de tumores malignos e de lesões altamente suspeitas de câncer à mamografia.

Caso a biópsia com agulha grossa não seja conclusiva, realiza-se biópsia incisional peroperatória, ou biópsia excisional, de acordo com cada caso.

Enquanto se aguarda o resultado do exame anátomo-patológico, solicitam-se os exames do pré-operatório. 


\section{AVALIAÇÃO DA EXTENSÃO DO TUMOR}

Para as pacientes com alta suspeita de tumor mamário maligno, mas ainda sem confirmação cito- ou histopatológica de malignidade, e para aquelas com diagnóstico firmado de câncer de mama, solicita-se:

- Radiografia simples de tórax em PA e perfil ( $R X$ de tórax), independentemente do estádio clínico do tumor.

- Fosfatase alcalina (FA), AST (TGO) e ALT (T GP) séricas, cintigrafia óssea e ultrasonografia (US) do abdômen superior, nos estádios II, III e IV.

O bservação: Cintigrafia óssea ou US do abdômen superior são também solicitadas em casos de estádios I e IIA, desde que a doente apresente sintoma ou sinal que justifiquem tal solicitação.

\section{AVALIAÇÃO DAS CONDIÇÕES CLÍNICAS DA PACIENTE}

\section{Exames pré-operatórios:}

- H emograma Completo (inclui contagem diferencial e plaquetometria);

- Creatinina sérica;

- Glicemia, se a doente tiver mais de 40 anos ou história pessoal e familiar de diabetes.

- ECG, se a doente tiver mais de 40 anos, história pessoal ou sintoma ou sinal de hipertensão arterial ou cardiopatia;

- Risco cirúrgico, se a doente tiver mais de 60 anos, história pessoal ou sintoma ou sinal de hipertensão arterial ou cardiopatia.

Para o tratamento de uma paciente com câncer de mama, deve-se, inicialmente, considerar a finalidade deste tratamento, se curativa, paliativa ou "higiênica". D eve-se também levar sempre em consideração as doenças associadas que porventura a mulher tenha, como cardiopatias, insuficiência renal e hepática, doenças reumáticas, distúrbios psiquiátricos, etc.

\section{TRATAMENTO}

\section{TRATAMENTO POR ESTÁDIO}

ESTÁDIO 0 - TISNOMO (CARCINOMA IN SITU)

0 carcinoma in situ de mama subdivide se em carcinoma ductal in situ (CDIS) e carcinoma lobular in situ (CLIS).

O CLIS é um achado, sendo, na maioria das vezes, diagnosticado incidentalmente no momento de uma biópsia. É uma lesão pré maligna, e o seu tratamento consiste de ressecção da lesão e seguimento da mulher, com exame físico e mamografias periódicas.

Para as mulheres que apresentam CDIS, dependendo da avaliação do médico eda opção da paciente, pode-se indicar a mastectomia e cirurgia reconstrutora imediata. O CDIS pode se manifestar como microcalcificações agrupadas, tumores ou secreção papilar. $\mathrm{N}$ as pacientes com microcalcificações agrupadas, procede-se à localização pré-operatória, orientada por estereotaxia, executando-se, a seguir, a ressecção da área com margem de segurança (limites marcados com fio cirúrgico), seguida da radiografia da peça operatória.

Após estudo minucioso da peça, e adotando-se 0 índice de Van N uys modificado (ver o quadro a seguir), determina-se o melhor tratamento para o caso, baseando-se nos resultados da soma dos respectivos valores: tamanho do tumor (em $\mathrm{mm}$ ), margens cirúrgicas livres de neoplasia (em $\mathrm{mm}$ ) e classificação histopatológica do tumor. Para os casos em que soma desses valores é de 3 a 7, recomenda-se a excisão ampla seguida de RT (Esquema 1, especificado adiante) e, nos casos cuja soma é de 8 e 9, na dependência da relação entre o tamanho da lesão e 0 volume da mama, indica-se a ressecção da lesão seguida de RT (Esquema 1) ou, quando a lesão for difusa, indica-se a mastectomia sem radioterapia pós-operatória.

\begin{tabular}{|c|c|c|c|}
\hline Escore/Descrição & 1 & 2 & 3 \\
\hline Tamanho (mm) & $<15$ & $16-40$ & $>40$ \\
\hline Margens (mm) & $>10$ & $1-9$ & $<1$ \\
\hline $\begin{array}{l}\text { Classificação } \\
\text { Histopatológica }\end{array}$ & $\begin{array}{l}\text { Baixo grau } \\
\text { (sem necrose) }\end{array}$ & $\begin{array}{l}\text { Baixo grau } \\
\text { (com necrose) }\end{array}$ & $\begin{array}{l}\text { Alto grau } \\
\text { (com/sem necrose) }\end{array}$ \\
\hline
\end{tabular}

D oença de Paget - É uma forma especial do câncer de mama, que compromete a papila, com característica histopatológica específica, podendo estar acompanhada de lesão subjacente, palpável ou não. Em caso do acometimento exclusivo da papila, realiza-se a chamada biópsia "diferida", ou seja, aguardase o resultado do exame histopatológico do material biopsiado incluso em parafina. 
Confirmado o diagnóstico, procede-se à centralectomia, englobando-se o complexo aréolo-papilar. No caso de a lesão associada ser um tumor, a conduta adotada depende do resultado do exame patológico (de biópsia por congelação) e da relação entre as dimensões do tumor e o volume da mama, de modo a permitir uma cirurgia conservadora, salvo outras contra-indicações.

Q uando o resultado anátomo-patológico da biópsia por congelação revelar carcinoma ductal in situ e for possível proceder-se à cirurgia conservadora, apenas a centralectomia será realizada, com 0 adequado exame das margens cirúrgicas. C aso não haja acome timento das margens, indica-se a radioterapia pós-operatória (Esquema 1); mas, se as margens estiverem acometidas, inclusive após a reexcisão, procede-se à mastectomia simples (sem esvaziamento axilar e sem radioterapia pós-operatória).

Q uando a histopatologia for carcinoma ductal infiltrante ou carcinoma lobular infiltrante e for possível a cirurgia conservadora (central ectomia), esta será realizada. D urante a cirurgia, não havendo acometimento de margem de ressecção, procede-se ao esvaziamento axilar (que, no IN CA, ainda inclui os três níveis - indicação sob revisão, inclusive por conta da incorporação do método de análise de linfonodo sentinela).

A radioterapia é efetuada tão logo ocorra a cicatrização da ferida operatória ou terminada a QT adjuvante com antracíclicos, conformeo estádio tumoral eo tipo decirurgia efetuado (centralectomia ou mastectomia): Esquema 1 ou 3 (especificado adiante) para o caso do estádio patológico com pN 0 linfonodos livres deneoplasia ou pN 1 - menos de quatro linfonodos axilares acometidos; ou Esquema 2 ou 4 (especificados adiante), para o caso de estádio patológico com pN 1 - quatro ou mais linfonodos acometidos, ou tumor maior que $5 \mathrm{~cm}$, ou presença de todos os três fatores seguintes, também de risco de recidiva local: tumor pouco diferenciado, necrose tumoral intensa e presença de êmbolos vasculares sangüíneos ou linfáticos.

Já no caso de margem acometida, realizase a reexcisão e, na persistência desse acometimento, a mastectomia com esvaziamento axilar, seguido, ou não, de radioterapia (Esquema 3 ou 4, conforme indicação descrita no parágrafo anterior).

\section{ESTÁDIO I - TINOMO}

$N$ esses casos, a biópsia per-operatória pela técnica de congelação é a modalidade cirúrgica inicial utilizada. A peça oriunda da biópsia também servirá para estudo dos receptores tumorais hormonais (RE e RP).

$N$ os casos de tumores de até $2 \mathrm{~cm}$, indicase a ressecção segmentar, englobando a cicatriz prévia da biópsia, e o estudo das margens cirúrgicas por exame de congelação. Então, prossegue-se com o tratamento, de acordo com os resultados obtidos:

CDI/CLI - Se margens cirúrgicas livres, procede-se ao esvaziamento axilar e, em seguida, RT (Esquema 1, seo estádio patológico for também com pN 0 ou pN 1 - menos de quatro linfonodos axilares acometidos; ou Esquema 2, se 0 estádio patológico for com pN 1 - quatro ou mais linfonodos axilares acometidos).

CDI/CLI - Se margem cirúrgica acometida, faz-se a reexcisão e, caso fiquem as margens livres de neoplasia, procede-se como no parágrafo anterior. Persistindo, porém, 0 acometimento marginal, procedese, então, à mastectomia com esvaziamento axilar, ficando a RT indicada conforme a situação dos linfonodos axilares (Esquema 2, se o estádio patológico for com pN 1 - quatro ou mais linfonodos axilares acometidos).

Deve-se considerar, à indicação da cirurgia conservadora, a relação tumor/ mama, 0 aspecto do tumor na mamografia, 0 desejo da paciente quanto à preservação da mama e o aspecto estético resultante da cirurgia conservadora.

Se um componente intra-ductal extenso estiver presente (no tumor ou, grosseiramente, no tecido normal adjacente), procede-se a uma ressecção mais alargada para remover 0 carcinoma residual. Se isso produzir um resultado cosmético inaceitável, será, então, indicada a mastectomia.

A abordagem da axila será feita, quando possível, mediante a própria incisão da segmentectomia, caso o tumor esteja no Q SE (quadrante superior externo). No caso de 0 tumor estar localizado nos demais quadrantes, faz-se uma segunda incisão, especificamente para o esvaziamento axilar. 


\section{ESTÁDIO IIA}

\section{TON1MO OU TXN1MO}

$N$ esses casos, após a confirmação histopatológica da origem mamária da invasão axilar, indica-se o esvaziamento axilar completo. A lesão oculta mamária pode ser do Q SE, local de maior quantidade do parênquima mamário. Em alguns casos, quando a mamografia apresenta anormalidade, pode-se realizar a retirada desse quadrante, junto com 0 esvaziamento axilar, durante 0 mesmo ato operatório e pela mesma incisão. É indicada também a RT (Esquema 1 ou 2, dependendo do número de linfonodos acometidos).

\section{TIN1MO e T2NOMO}

N esse caso, cirurgia conservadora (ressecção segmentar) é possível desde que: - não haja mais de um tumor mamário;

- a relação tumor/mama apresente boa margem de segurança e levando-se também em consideração o padrão mamográfico;

- a disponibilidade do estudo por congelação das margens cirúrgicas; e

- o desejo da paciente de esse seja o tipo de cirurgia considerado.

Geralmente, para a confirmação do diagnóstico, opta-se pela biópsia com agulha grossa. Entretanto, a biópsia por congelação também é uma modalidade possível de ser adotada. No caso de cirurgia conservadora, obriga-se 0 estudo das margens da peça operatória por exame de congelação. D e acordo com o resultado deste, adota-se um dos seguintes procedimentos:

CDI/CLI com margens cirúrgicas livres: fazse 0 esvaziamento axilar e indica-se a RT (Esquema 1 ou 2, dependendo do número de linfonodos acometidos ao estadiamento patológico pN 1).

CDI/CLI com margem acometida: faz-se a reexcisão, procedendo-se como no parágrafo anterior, se as margens ficarem livres. Caso, ao exame de congelação, persista 0 acometimento marginal, opta-se pela mastectomia com esvaziamento axilar, e RT nas pacientes com risco de recidiva local (Esquema 3 ou 4, dependendo do número de linfonodos acometidos ao estadiamento patológico pN 1). 0 risco de recidiva local é caracterizado por todos os seguintes fatores: tumor pouco diferenciado, necrose tumoral intensa e presença de êmbolos vasculares sangüíneos ou linfáticos.

\section{ESTÁDIO IIB}

\section{T2N1MO e T3NOMO}

Como nos estádios anteriores, desde que haja as indicações para o tratamento conservador, este deve ser realizado. As pacientes são submetidas ou à biópsia com agulha grossa ou à biópsia per-operatória (exame histopatológico em congelação) e segmentectomia englobando a cicatriz prévia da biópsia, com estudo das margens cirúrgicas, também peroperatório. De acordo com os resultados deste, a conduta adotada será:

CD I/CLI - M argens cirúrgicas livres: esvaziamento axilar e RT (Esquema 1 ou 2, dependendo do número de linfonodos acometidos ao estadiamento patológico pN 1).

CDI/CLI - M argem cirúrgica acometida: fazse a reexcisão, procedendo-se como no parágrafo anterior, se as margens ficarem livres. Em caso de persistência do acometimento marginal, é indicada a mastectomia com esvaziamento axilar, eRT nas pacientes de risco de recidiva local ou loco-regional (Esquema 3 ou 4, dependendo do número de linfonodos acometidos ao estadiamento patológico pN 1).

\section{ESQUEMAS DE RADIOTERAPIA}

Esquema 1 - Radioterapia sobre mama e parede torácica com unidade de cobalto ou acelerador linear de 4-6 M V, na dose de 5.000 cG y divididos em 25 frações, em campos tangenciais, 02 campos por fração, num total de 50 campos em 25 dias úteis. Total do Esquema $1=50$ campos.

Esquema 2 - Radioterapia sobre mama e parede torácica, na dose de 5.000 cG y divididos em 25 frações. A mama é irradiada por meio de unidade de cobalto ou acelerador linear de 4-6 M V, em campos tangenciais, 02 campos por fração, num total de 50 campos em 25 dias úteis. As cadeias linfáticas supraclavicular e axilar homolaterais são irradiadas, por meio de unidade de cobalto ou acelerador linear de 4-6 M V, em campo ântero-posterior, 02 
campos por fração, num total de 50 campos. Total do Esquema $2=100$ campos.

E squema 3 - Radioterapia sobre parede torácica (plastrão) na dose de 5.000 cG y divididos em 25 frações, em campos tangenciais, 02 campos por fração, num total de 50 campos em 25 diasúteis, quando utilizado feixe defótons (unidade de cobalto ou acelerador linear de 4-6 M V). A utilização de feixe de elétrons de 6-9 M EV (acelerador com energia superior a $8 \mathrm{M} \mathrm{V}$ ) requer apenas a utilização de 01 campo por fração num total de 25 campos. Total do Esquema $3=50$ campos (fótons) ou 25 campos (elétrons).

Esquema 4 - Radioterapia sobre parede torácica (plastrão) na dose de 5.000 cG y divididos em 25 frações, em campos tangenciais, 02 campos por fração, num total de 50 campos em 25 diasúteis, quando utilizado feixe de fótons (unidade de cobalto ou acelerador linear de 4-6 MV). A utilização de feixe de elétrons de 6-9 M EV (acelerador com energia superior a $8 \mathrm{MV}$ ) requer apenas a utilização de 01 campo por fração num total de 25 campos. As cadeias linfáticas supraclavicular e axilar homolaterais são irradiadas, por meio de unidade de cobalto ou acelerador de 4-6 M V, em campo ântero-posterior, 02 campos por fração, num total de 50 campos. Total do Esquema 4 = 100 campos (só fótons) ou 75 campos (fótons e elétrons).

Nota: Pacientes sob QT adjuvante com antracíclico, combinada à RT, aguardam 0 término da QT e do nadir, para o início da RT. Tal recomendação não se aplica ao uso combinado de RT e QT com CMF ou de RT eHT com tamoxifeno (Tam).

\section{TERAPIA SISTÊMICA}

\section{Quimioterapia e Hormonioterapia Adjuvantes - Estádios I e II}

N os estádios I, IIA e IIB, a quimioterapia (QT) e a hormonioterapia (H T) adjuvantes serão indicadas nas seguintes situações:

Linfonodo axilar negativo

- Risco baixo (Todos os seguintes critérios: Tumor $<1 \mathrm{~cm}, \mathrm{RE}+$ ou RP+, grau histopatológico I e idade $>35$ anos)
Seguimento periódico.

- Risco intermediário (Tumor de 1-2 cm, RE + ou RP +, grau histopatológico I ou II e idade $>35$ anos.)

Pré-menopausa - AC x 4 à Tam $\times 5$ anos ( $\mathrm{H}$ T seqüencial à Q $\mathrm{T}$ )

Pós-menopausa - Tam x 5 anos (Em casos individualizados, também AC $\times 4$.)

- Risco elevado (Q ualquer dos seguintes critérios: Tumor $>2 \mathrm{~cm}$, grau histopatológico II ou III e idade $<35$ anos.)

\begin{tabular}{|c|c|c|}
\hline ESTADO/RECEPTOR & RE + ou RP + & $R E-e ~ R P$ - \\
\hline Pré-menopausa & $\begin{array}{l}\text { AC x } 4 \text { à Tam x } 5 \text { anos } \\
\text { (HT seqüencial à QT) }\end{array}$ & $A C \times 4$ \\
\hline Pós-menopausa & $\begin{array}{l}\text { AC x } 4 \text { à Tam x } 5 \text { anos } \\
\text { (HT seqüencial à QT) }\end{array}$ & $A C \times 4$ \\
\hline Idade $>70$ anos & $\begin{array}{l}\text { Tam x } 5 \text { anos [Em casos } \\
\text { individualizados, AC x } 4 \\
\text { à Tam } \times 5 \text { anos } \\
\text { (HT seqüencial à QT).] }\end{array}$ & $\begin{array}{l}\text { (Em casos individuali- } \\
\text { zados, } A C \times 4 \text {.) }\end{array}$ \\
\hline
\end{tabular}

Q uadro 2 - Estados e receptores em linfonodo axilar negativo

Nota 1: Em todos as situações de linfonodo axilar negativo, indica-se CM F clássico X 6 , no lugar de $A C X$ 4, na contra-indicação do uso da doxorrubicina (adriamicina).

Nota 2: $\mathrm{N}$ a intolerância ao CM F clássico, aplicam-se os 06 ciclos de CMF em administração IV, de 28/28 dias, com a CTX, da mesma forma quea 5FU e o M TX, aplicada nos $1^{\circ}$ e $8^{\circ}$ dias (e não durante 14 dias - V0).

Linfonodo axilar positivo

- Menos de quatro linfonodos axilares acometidos

\begin{tabular}{|c|c|c|}
\hline ESTADO/RECEPTOR & $\mathrm{RE}+$ ou RP + & $R E-e$ RP - \\
\hline Pré-menopausa & $\begin{array}{l}\text { AC x } 4 \text { à Tam x } 5 \text { anos } \\
\text { (HT seqüencial à QT) }\end{array}$ & $A C \times 4$ \\
\hline Pós-menopausa & $\begin{array}{l}\text { AC x } 4 \text { à Tam x } 5 \text { anos } \\
\text { (HT seqüencial à QT) }\end{array}$ & $A C \times 4$ \\
\hline Idade $>70$ anos & $\begin{array}{l}\text { Tam x } 5 \text { anos } \\
\text { [Em casos individualizados, } \\
\text { AC x } 4 \text { à Tam x } 5 \text { anos } \\
\text { (HT seqüencial à QT).] }\end{array}$ & $A C \times 4$ \\
\hline
\end{tabular}

Quadro 3 - Estados e receptores em linfonodo axilar positivo

Nota 1: Em todos as situações de menos de quatro linfonodos axilares acometidos, indica-se CM F clássico X 6, no lugar de AC $X$ 4, na contra-indicação do uso da doxorrubicina.

Nota 2: N a intolerância ao CM F clássico, aplicam-se os 06 ciclos de CMF em 
administração IV, de 28/28 dias, com a CTX, da mesma forma quea $5 F U$ eo M TX, aplicada nos $1^{\circ}$ e $8^{\circ}$ dias (e não durante 14 dias - VO).

\section{- Q uatro ou mais linfonodos axilares acometidos}

$\begin{array}{ll}\mathrm{RE}+\mathrm{ou} \mathrm{RP}+ & \mathrm{RE}-\mathrm{e} \mathrm{RP}- \\ \mathrm{A} \times 4 \rightarrow \mathrm{CMF} \times 8 & \mathrm{~A} \times 4 \rightarrow \mathrm{CMF} 8 \\ \rightarrow \text { Tam } \times 5 \text { anos } & \\ \text { (HT seqüencial à QT) } & \\ \begin{array}{l}\text { Q uadro 4 - Receptores para } 4 \\ \text { acometidos }\end{array} & \end{array}$

Nota 1: Em todos as situações de quatro ou mais linfonodos axilares acometidos, após o $A X 4$, utiliza-se o CM $F$ modificado (administração IV - 21/21 dias).

N ota 2: Em todos as situações de quatro ou mais linfonodos axilares acometidos, indica-se CM F clássico X 6 , no lugar de A $x$ 4 à CM F x 8, na contra-indicação do uso da doxorrubicina.

Nota 3: N a intolerância ao CM F clássico, aplicam-se os 06 ciclos de CMF em administração IV, de 28/28 dias, com a CTX, da mesma forma quea 5FU eo M TX, aplicada nos $1^{\circ}$ e $8^{\circ}$ dias (e não durante 14 dias - VO).

N ota 4: D iscutida no Conselho de Bioética do IN CA, a indicação de taxano adjuvante é pendente de estudos de resultados finais e análise econométrica que definam a eficiência desse tratamento, em termos de benefício/ custo, eficácia/custo e utilidade/custo.

\section{RECONSTRUÇÃO MAMÁRIA}

Indica-se para depois do término da quimioterapia adjuvante, ou para qualquer tempo, quando a mulher não recebe terapia adjuvante ou apenas recebe hormonioterapia adjuvante.

ESTÁDIO III

\section{Estádio IIIA - T0-T2N2MO ou T3N1-N2MO}

\section{Estádio IIIB - T4NqualquerMO ou TqualquerN3MO}

O estádio III (tumor localmente avançado) é classificado em operável e inoperável.
Tumor operável

A conduta cirúrgica para estes casos é a biópsia per-operatória seguida de mastectomia com esvaziamento axilar. A mastectomia tipo $\mathrm{H}$ alsted modificada é realizada nas pacientes nas quais o tumor invade o músculo grande peitoral. Indica-se, então, seqüencialmente, RT (Esquema 3 - margem profunda livre e pN 0 ou pN 1 com menos de quatro linfonodos acometidos; ou Esquema 4 margem profunda livre e pN 1 com quatro ou mais linfonodos acometidos, pN 2 ou pN 3; ou Esquema 5 (ver adiante) - margem profunda minimamente livre e pN 0 ou pN 1 com menos de quatro linfonodos acometidos; ou Esquema 6 (ver adiante) - margem profunda minimamente livre e pN 1 com quatro ou mais linfonodos acometidos, pN 2 ou pN 3) e QT ou HT adjuvantes.

\section{Tumor inoperável}

0 procedimento inicial é a biópsia com agulha grossa ou a biópsia incisional, para a confirmação patológica de malignidade e avaliação dos receptores hormonais (RE eRP), seguida de quimioterapia prévia (neoadjuvante), com 04 ciclos de doxorrubicina isolada.

Se ocorrer resposta objetiva a essa QT, realizar-seá a mastectomia com esvaziamento axilar, seguida de RT (Esquema 5 ou 6, na dependência do estadiamento patológico dos linfonodos axilares) e QT ou HT adjuvantes.

Se não se observar resposta à QT prévia, ou na progressão tumoral na vigência dessa QT, a RT será indicada (Esquema 6), que terá finalidade prévia, caso torne o tumor operável; se não, terá finalidade de controle local ou paliativa.

Em casos excepcionais, individualizados, na falha ou contra-indicação da QT, e desde que RE + ou RP +, é tentada a HT prévia, combinada, ou não, à RT.

\section{ESQUEMAS DE RADIOTERAPIA}

Esquema 5 - Radioterapia sobre parede torácica (plastrão) na dose de 5.000 cG y divididos em 25 frações, em campos tangenciais, 02 campos por fração, num total de 50 campos em 25 diasúteis, quando utilizado feixe defótons (unidade de cobal to 
ou acelerador linear de 4-6 M V). A utilização de feixe de elétrons de 6-9 M EV (acelerador com energia superior a $8 \mathrm{M} \mathrm{V}$ ) requer apenas a utilização de 01 campo por fração, num total de 25 campos. D ose de reforço (boost) sobre o leito tumoral: $1.000 \mathrm{cG}$, divididos em 05 frações, em campos tangenciais, 02 campos por fração, num total de 10 campos em 05 dias úteis, quando utilizado feixe de fótons (unidade de cobalto ou acelerador linear de 4-6 M V). A utilização de feixe de elétrons de 6-9 M EV (acelerador com energia superior a $8 \mathrm{MV}$ ) requer apenas a utilização de 01 campo por fração, num total de 05 campos. Total do Esquema $5=60$ campos (fótons) ou 30 campos (elétrons).

Esquema 6 - Radioterapia sobre parede torácica (plastrão) na dose de 5.000 cG y divididos em 25 frações, em campos tangenciais, 02 campos por fração, num total de 50 campos em 25 dias úteis, quando utilizado feixe de fótons (unidade de cobalto ou acelerador linear de 4-6 M V). A utilização de feixe de elétrons de 6-9 M EV (acelerador com energia superior a $8 \mathrm{M} \mathrm{V}$ ) requer apenas a utilização de 01 campo por fração, num total de 25 campos. D ose de reforço (boost) sobre o leito tumoral: 1.000 cG y, divididos em 05 frações, em campos tangenciais, 02 campos por fração, num total de 10 campos em 05 diasúteis, quando utilizado feixe de fótons (unidade de cobalto ou acelerador linear de 4-6 MV). A utilização de feixe de elétrons de 6-9 M EV (acelerador com energia superior a $8 \mathrm{M} \mathrm{V}$ ) requer apenas a utilização de 01 campo por fração, num total de 05 campos. As cadeias linfáticas supraclavicular e axilar homolaterais são irradiadas, por meio de unidade de cobalto ou acelerador de 4-6 M V, em campo ântero-posterior, 02 campos por fração, num total de 50 campos. Total do Esquema $6=110$ campos (só fótons) ou 80 campos (fótons e elétrons).

\section{TERAPIA SISTÊMICA}

\section{Quimioterapia e Hormonioterapia Adjuvantes - Estádio III}

Estádio III - Tumor operável As mesmas indicações para o câncer de mama em estádios I, IIA e IIB, inclusive no caso de Linfonodo axilar negativo - Risco elevado.

Estádio III - Tumor inoperável que se tornou operável após QT, RT ou HT

$\mathrm{RE}+$ ou RP + RE - e RP -

CMF (IV - 21/21 dias) $\times 8 \rightarrow$ Tam $\times 5$ anos CMF (IV - 21/21 dias) $\times 8$

(HT seqüencial à $Q T)$

Quadro 5 - Receptores para tumores operáveis após terapias

Estádio III - Tumor inoperável

mesmo após QT, RT ou HT

Seguimento periódico e cuidados

paliativos.

ESTÁDIO IV (Tqualquer Nqualquer MI) E

CÂNCER RECIDIVADO (recidiva loco-regional ou com metástase à distância)

N os casos de estádio IV, indica-se a mastectomia apenas se a finalidade for "higiênica" ou, em casos excepcionais, paliativa.

$\mathrm{N}$ os casos de câncer de mama localmente recidivado, separam-se as pacientes que receberam tratamento cirúrgico radical do conservador. No primeiro caso, se a recidiva ocorreu no plastrão e é ressecável, procedese à ressecção cirúrgica, seguida de RT (Esquema 4 a 6, dependendo do resíduo), se esta não tenha sido aplicada anteriormente.

$\mathrm{N}$ os casos de cirurgia conservadora, dependendo do grau de dificuldade de se fazer o diagnóstico da recidiva, apresentam-se duas opções: nova cirurgia conservadora (com esvaziamento axilar, caso este não tenha sido feito anteriormente) ou a mastectomia (idem, ibidem), complementando-se esta com a RT (Esquema 4 a 6, dependendo do resíduo), caso esta também não tenha sido antes aplicada.

As demais utilizações de radioterapia e tratamento sistêmico, para os casos em estádio IV ou recidivados, são utilizados conforme se segue.

\section{RADIOTERAPIA - ESTÁDIO IV OU TUMOR RECIDIVADO}

\section{Situação 1 - RT de recidiva com} metástase solitária

Pacientes com metástase isolada sinto- 
mática e de qualquer localização recebe RT (concomitantemente, ou não, à QT ou H T), preferencialmente com $3.000 \mathrm{cG}$ y em 10 frações.

\section{Situação 2 - RT de recidiva com metástases ósseas múltiplas}

Indicação: M etástases ósseas em pontos de sustentação esquelética com acometimento cortical, sintomáticas ou não, independentemente da concomitância do tratamento sistêmico, e lesões sintomáticas de difícil controle analgésico.

Esquemas radioterápicos: 800 cG y em uma dose única; $2.000 \mathrm{cG}$ y em 05 frações de 400 cG y; ou 3.000 cGy em 10 frações de 300 cG y. Nota 1: Esses esquemas têm poder equivalente de paliação dos sintomas, porém a maior duração dessa paliação é obtida com um maior fracionamento da dose. Nota 2: A RT paliativa é também indicada após cirurgia ortopédica por metastáse óssea, quando esta é procedida.

\section{Situação 3 - RT de Urgência}

M etástase C erebral: D exametasona $10 \mathrm{mg}$ IV em pulso, com dose de manutenção de $4 \mathrm{mg}$ V0 6/6 horas, e RT craniana: $2.000 \mathrm{cG} \mathrm{y}$ em 5 frações, 02 campos por fração, num total de 10 campos.

Compressão da M edula Espinhal: D exametasona conforme o esquema acima, e RT com frações de, no mínimo, 400 cGy, preferencialmente 2.000 cG y em 05 frações.

Síndrome de Compressão da Veia C ava Superior: D exametasona conforme o esquema acima. Independentemente de RT anterior, frações de, no mínimo, 400 cGy, preferencialmente 2.000 cG y em 05 frações, ou 800 cG y em uma única fração.

\section{TERAPIA SISTÊMICA PALIATIVA - Estádio IV ou tumor recidivado}

\section{Situação 1 - Hormonioterapia paliativa}

Indicações: RE + ou RP +, obrigatoriamente. $M$ etástases ósseas ou de partes moles, inclusive linfonodais; metástase pulmonar nodular assintomática; longo intervalo livre de doença; e metástases solitárias indolentes.
Pré-menopausa

$1^{\text {a }}$ linha- Tamoxifeno $\rightarrow 2^{\text {a }}$ linhaO oforectomia bilateral ou ablação actínica ( 0 u vice versa: $1^{\text {a }}$ linha- 0 oforectomia bilateral ou ablação actínica $\rightarrow 2^{\text {a }}$ linha- Tamoxifeno) $\rightarrow 3^{\text {a }}$ linha I nibidor da aromatase $\rightarrow 4^{\mathrm{A}}$ linhaAcetato de megestrol.

Nota: A dose de RT para ablação ovariana é de 1.500 em 03 frações de 500 cGy, 02 campos por fração, num total de 06 campos em 03 dias úteis; ou 2.000 cG y, em 05 frações de 400 cG y por fração, 02 campos por fração, num total de 10 campos em 05 dias úteis.

\section{Pós-menopausa}

$1^{\text {a }}$ linha- Tamoxifeno $\rightarrow 2^{\text {a }}$ linha- Inibidor da aromatase $\rightarrow 3^{\text {a }}$ linha- Acetato de megestrol.

Nota 1: A prescrição de uma linha subse qüente de H T está condicionada à existência de resposta à linha antecedente.

Nota 2: N o caso de recidiva tumoral dentro de 2 ou mais anos após H T adjuvante com tamoxifeno, este mesmo antiestrogênio poderá ser de novo utilizado, com finalidade paliativa.

Nota 3: A HT paliativa tem mudança de linha, ou é suspensa, na existência de progressão tumoral.

\section{Situação 2 - Quimioterapia paliativa}

Indicações: Progressão na vigência de $\mathrm{H}$ T; RE e RP negativos; recidiva precoce; lesão visceral sintomática (no pulmão, linfangite carcinomatosa).

Sem Quimioterapia Adjuvante

Anterior

- 1a linha- CM F (IV - 21/21 dias) ou esque ma que contenha antracíclico $\rightarrow 2^{\text {a }}$ linhaD ocetaxel (acometimento metastático visceral, com metástases hepáticas, linfangite carcinomatosa ou nódulos pulmonares) ou C apecitabina (acometimento metastático cutâneo, linfonodal ou ósseo).

N ota 1: 0 seguinte é possível: $1^{\text {a }}$ linhaCM F (IV - 21/21 dias) - Sem resposta $\rightarrow 2^{\text {a }}$ linha- D oxorrubicina isolada $\rightarrow 3^{\text {a }}$ linha (Se houve ótima resposta à $2^{\mathrm{a}}$ linha)- D ocetaxel (acometimento metastático visceral, com metástases hepáticas, linfangite carcinomatosa ou nódulos pulmonares) ou Capecitabina (aco- 
metimento metastático cutâneo, linfonodal ou ósseo).

Nota 2: A quimioterapia paliativa só é mantida, se se verifica resposta objetiva, e sua duração é de até 02 ciclos depois de obtida a resposta objetiva máxima, inclusive obede cendo-se o limite de dose de antracíclico.

Com Quimioterapia Adjuvante Anterior

- Uso anterior de AC ou de FAC: Linha única- $D$ ocetaxel (acometimento metastático visceral, com metástases hepáticas, linfangite carcinomatosa ou nódulos pulmonares) ou Capecitabina (acometimento metastático cutâneo, linfonodal ou ósseo).

- U so anterior de CM F há menos de 2 anos: $1^{\text {a }}$ linha- D oxorrubicina isolada $\rightarrow 2^{\text {a }}$ linhaD ocetaxel (acometimento metastático visceral, com metástases hepáticas, linfangite carcinomatosa ou nódulos pulmonares) ou Capecitabina (acometimento metastático cutâneo, linfonodal ou ósseo).

- U so anterior de CM F há mais de 2 anos: 1 linha- CM F (IV - 21/21 dias) ou esquema que contenha antracíclico $\rightarrow 2^{\text {a }}$ linhaD ocetaxel (acometimento metastático visceral, com metástases hepáticas, linfangite carcinomatosa ou nódulos pulmonares) ou C apecitabina (acometimento metastático cutâneo, linfonodal ou ósseo).

N ota 1: N o caso de uso anterior de CM F há mais de 2 anos, 0 seguinte é possível: $1^{\text {a }}$ linha- CM F (IV - 21/21 dias) - Sem resposta $\rightarrow 2^{\text {a }}$ linha- D oxorrubicina isolada $\rightarrow 3^{\text {a linha }}$ (Se houveótima respostaà $2^{\text {a }}$ linha)- D ocetaxel (acometimento metastático visceral, com metástases hepáticas, linfangite carcinomatosa ou nódulos pulmonares) ou Capecitabina (acometimento metastático cutâneo, linfonodal ou ósseo).

Nota 2: A quimioterapia paliativa só é mantida, se se verifica resposta objetiva, e sua duração é de até 02 ciclos depois de obtida a resposta objetiva máxima, inclusive obedecendo-se o limite de dose de antracíclico.

\section{Situação 3 - Lesões osteolíticas}

Inibidores de 0 steólise - Indicação: Lesões osteolíticas nas radiografias ósseas de mulheres, sintomáticas ou não, que estejam recebendo quimio- ou hormonioterapia e com doença neoplásica controlada. A terapia com os bisfosfonatos venosos, uma vez iniciada, será mantida até a evidência de progressão da doença óssea (evidência da ineficácia da quimio- ou hormonioterapia), de efeitos colaterais (hipocalcemia, por exemplo) e de declínio da capacidade funcional (perfomance status - PS). Inibidor e posologia: Pamidronato dissódico - 90mg - IV, a cada 3 ou 4 semanas.

\section{SEGUIMENTO DA PACIENTE TRATADA}

0 tratamento da recidiva local, ou de um outro tumor na mama contra-lateral, interfere na história natural do câncer de mama, enquanto 0 tratamento da metástase, não. Por isso, na ausência de sintomas, os exames de seguimento são apenas dois: exame físico completo (o exame ginecológico é imprescindível no caso de hormonioterapia adjuvante com tamoxifeno) e mamografia (bilateral ou da mama restante, se a mulher foi mastectomizada).

A mamografia é feita anualmente, inclusive durante a hormonioterapia adjuvante, enquanto que cintigrafia óssea, RX de Tórax, US abdominal ou outros exames somente são solicitados quando haja sintoma a esclarecer.

Terminado o tratamento adjuvante, 0 acompanhamento ambulatorial é semestral, caso a cirurgia tenha sido conservadora; ou anual, se se procedeu à mastectomia.

\section{FORMAS ESPECIAIS DE CÂNCER MAMÁRIO}

\section{CARCINOMA INFLAMATÓRIO}

O carcinoma inflamatório de mama é uma forma clínica especial de carcinoma mamário que apresenta sinais inflamatórios (eritema, edema cutâneo e pele tipo casca de laranja), de rápida evolução e mau prognóstico, não havendo uma histopatologia peculiar que o diferencie dos demais tipos de carcinoma, a não ser a presença de êmbolos neoplasicos nos linfáticos cutâneos e subcutâneos.

Para o tratamento do carcinoma inflamatório de mama, utilizam-se as mesmas condutas de QT e RT (Esquema 4) descritas para 0 estádio IIIB. 


\section{CÂNCER DE MAMA BILATERAL}

0 câncer bilateral de mama pode ser sincrônico ou assincrônico.

\section{Sincrônico}

D etectado, simultaneamente, em ambas as mamas, antes da realização do primeiro tratamento. Do ponto de vista terapêutico, ele pode ser:

- O perável: quando obedece de ambos os lados os critérios estabelecidos para o câncer operável unilateral.

- Inoperável: quando não obedece de um ou ambos os lados os critérios estabelecidos para o câncer operável unilateral. N esse caso, o tratamento é idêntico ao recomendado para o câncer inoperável unilateral, seja localmente avançado de um ou de ambos os lados, ou com metástase à distância.

Nota: As indicações de RT adjuvante são similares àquelas do câncer unilateral, podendo inclusive ser bilateralmente simultânea.

\section{Assincrônico}

D etectado após o diagnóstico de câncer em uma primeira mama afetada, em qualquer tempo, podendo ser primitivo ou metastático.

- Primitivo: quando é difícil estabelecer se o câncer da segunda mama afetada é primitivo ou metastático do primeiro. Os crité rios são variáveis, discutíveis e falhos. São considerados primitivos os casos de tipo ou subtipo histopatológico diferente; de tumor único; sem metástase à distância do câncer da primeira mama; sem sinais de disseminação local a partir da primeira mama afetada; e, exceto no carcinoma medular, cujo tumor esteja localizado no parênquima glandular e não nos tecidos de revestimento da glândula mamária; com áreas de transição nas imediações do tumor (hiperplasias epiteliais com atipias, carcinoma in situ, etc.).

A conduta terapêutica é a indicada para 0 câncer de mama, enquadrando-se no esquema acima apresentado para os casos operáveis ou inoperáveis.

- Metastático: quando não se enquadra nos critérios acima estabelecidos para o câncer primitivo.

A conduta terapêutica é idêntica à preconizada para o câncer metastático de mama unilateral.

\section{SARCOMA MAMÁRIO}

Em virtude da pequena freqüência e diversidade do comportamento biológico tumoral, o tratamento dos sarcomas é programado a partir de indicações individuais e baseado nas condições gerais da mulher e na história natural, tipo histopatológico e fase evolutiva do tumor.

O s seguintes aspectos são observados:

1.0 tratamento cirúrgico busca alcançar margens de segurança;

2.N ão se procede ao esvaziamento axilar;

3.N ão se aplica quimioterapia prévia nem adjuvante;

4.N ão se prescreve hormonioterapia de qualquer finalidade; e

5.A quimioterapia paliativa, quando indicada, considera o diagnóstico de sarcoma, e não a sua localização em mama.

\section{CÂNCER DA MAMA MASCULINA}

O s critérios de operabilidade são idênticos aos já mencionados para o câncer da mama feminina.

\section{Casos operáveis}

M astectomia radical modificada, seguida, ou não, de autoplastia cutânea, em virtude da escassez de pele.

\section{Casos inoperáveis}

0 mesmo tratamento adotado para os casos inoperáveis do câncer da mama feminina.

\section{Radioterapia}

As indicações são as mesmas do câncer da mama feminina, utilizando-se os esquemas $3,4,5$ ou 6 , em suas respectivas indicações. Relativamente à RT paliativa, todas as indicações descritas para o câncer da mama feminina aplicam-se ao da mama masculina.

\section{Terapia sistêmica}

- ADJUVANTE: QT e HT idênticas às descritas para os respectivos estádios do câncer da mama de mulher em pósmenopausa, inclusivecom a H T seqüencial à $Q T$.

- PRÉVIA: Como a descrita para a QT do câncer da mama feminina.

- QT PALIATIVA: 0 mesmo descrito para o câncer da mama feminino em estádio IV 
ou recidivado.

- HT PALIATIVA: $\mathbf{1}^{\text {a }}$ linha- TAM $\rightarrow \mathbf{2}^{\mathrm{a}}$ linha- O rquiectomia bilateral $\rightarrow 3^{a}$ linhaLetrozol

Nota 1: A prescrição de uma linha subseqüente de $\mathrm{HT}$ está condicionada à existência de resposta à linha antecedente.

N ota 2: No caso de recidiva tumoral dentro de 2 ou mais anos após QT ou HT adjuvantes, o(s) mesmo(s) medicamento(s) poderá(ão) ser de novo utilizado(s), com finalidade paliativa.

N ota 3: A QT ou HT paliativas têm mudança de linha, ou são suspensas, na existência de progressão tumoral.

Nota 4: A quimioterapia paliativa só é mantida, se se verifica resposta objetiva, e sua duração é de até 02 ciclos depois de obtida a resposta objetiva máxima, inclusive obedecendo-se o limite de dose de antracíclico.

\section{CÂNCER DE MAMA E GRAVIDEZ}

$\mathrm{N}$ a suspeita de tumor maligno, utiliza-se a PAAF ou a biópsia excisional.

Durante 0 estadiamento do tumor, evitase a mamografia, mesmo porque nessas pacientes, que são jovens e com parênquima mamário bastante denso, não se evidencia 0 tumor no seu interior. A cintigrafia óssea também esta contra-indicada durante a gravidez.

O s seguintes critérios são seguidos:

- Se com menos de 3 meses, não se indica formalmente o esvaziamento uterino.

- Se as margens cirúrgicas estiverem acometidas (em caso de biópsia excisional ou cirurgia conservadora), reopera-se a mama doente.

- A axila homolateral deve ser esvaziada, com ou sem reoperação da mama doente, pois há chance de $30 \%$ da axila ser clinicamente acometida e ser negativa ao exame clinico.

- Se procedida à cirurgia conservadora, indica-se a QT e RT adjuvantes, conforme já especificado por estádio.

- Seja após cirurgia conservadora ou mastectomia, posterga-se a RT para o pós-parto.

- Qualquer que seja a idade gestacional e a finalidade terapêutica, não se aplicam antimetabólitos nem tamoxifeno.

- Se com mais de 3 meses de gestação, não há contra-indicação de QT baseada em doxorrubicina.

- Apóa o parto, se RE + ou RP +, há duas possibilidades, após a QT adjuvante: Tamoxifeno por 5 anos ou ablação ovariana (cirúrgica ou actínica), na dependência do grau do risco de recidiva, da idade da mulher e do seu desejo de novamente engravidar.

NOTA FIN AL: Para o IN CA, qualquer conduta aplicada em suas unidades hospitalares que se encontre fora das aqui especificadas é considerada experimental ou irregular.

\footnotetext{
Abreviaturas: CDI - carcinoma ductal infiltrante; CDIS- carcinoma ductal in situ ; CDI-carcinoma ductal infiltrante; CLI - carcinoma lobular infiltrante; CIS- carcinoma in situ CDIS - carcinoma ductal in situ ; CLIS- carcinoma lobular in situ; RE - receptor tumoral de estrogênio; RP- receptor tumoral de progesterona; PAAF- punção aspirativa com agulha fina; FA fosfatase alcalina; TGO - Transaminase glutâmico-oxalo-acética; AST - Aspartato-amino-transferase; TGP - Transaminase glutâmico-pirúvica; ALT - Alanina-amino-transferase; US - ultra-sonografia; RX - radiografia simples; Tam - Tamoxifeno; CTX - ciclofosfamida; 5FU - 5-fluorouracila; M TX - metotrexato.
} 